\title{
Aleit Veenstra*, Philippe Meers and Daniël Biltereyst Exploring film genre preferences through taste cultures: A survey on contemporary film consumption amongst youth in Flanders (Belgium)
}

https://doi.org/10.1515/commun-2019-2032

\begin{abstract}
This article explores contemporary film genre preferences through an in-depth sociological analysis of taste cultures in film preferences amongst youth aged 16-18 in Flanders (the northern Dutch-speaking part of Belgium). Building on a representative sample of 1015 respondents we statistically analyze the assumption that contemporary media audiences demonstrate mobility and that they are eager to shape their media consumption in accordance with their personal preferences. This article examines whether societal structures that have been found to reflect media preferences remain in place, or whether these structures have eroded with the (supposed) increase in individual choice - an argument often voiced in the context of convergence culture. An analysis of the variables gender, educational level and ethnicity illustrates that societal structures are still reflected through film genre preferences amongst Flemish youth.
\end{abstract}

Keywords: audiences, taste cultures, film genre, youth

\section{Introduction}

In the early 2000s, the internet was celebrated as an ultimate tool for media participation. The concept of "convergence culture", introduced by Jenkins (2006), fits this enthusiasm seamlessly. He argues that existing media structures are tending to erode now that audiences can, and ultimately will, participate in their media environments. The resulting media landscape exists in "the flow of content across multiple media platforms, the cooperation between multiple media indus-

\footnotetext{
*Corresponding author: Aleit Veenstra, Department of Communication Studies, University of Antwerp, E-Mail: aleit.veenstra@uantwerpen.be.

Philippe Meers, Department of Communication Studies, University of Antwerp, E-Mail: philippe.meers@uantwerpen.be.

Daniël Biltereyst, Department of Communication Studies, Ghent University, E-Mail: daniel.biltereyst@ugent.be.
} 
tries, and the migratory behavior of media audiences who will go almost anywhere in search of the kinds of entertainment experiences they want" (Jenkins, 2006, p. 2).

This alleged audience mobility has drawn the attention of (film) audience researchers, who question the agency of audiences implied by the hunt for individualized media experiences (Biltereyst and Meers, 2011; Bird, 2011; Couldry, 2011). Stratification - the hierarchal structure of internalized values attributed to social characteristics - is a prominent concept in these critiques. Taste, these researchers argue, is not merely a matter of individual choice. Rather, it is a socially informed expression of societal structures. The consequence is, in the words of Couldry (2012): "If those who create online content (...) are stratified by gender and class, then the heralded transition from a 'read-only culture' to a 'read/write culture' is not assured" (p. 35).

This paper questions audience practices by exploring the reflection of societal structures through film genre preferences. In analyzing a representative sample of 1015 high school students aged 16 to 18 living in Flanders (the northern Dutch-speaking region of Belgium), we examine whether taste cultures surface. Since film exists in and beyond new technologies at the heart of a large cultural industry (Maltby, 1999), we argue that it is a valuable medium in understanding audiences' practices. In the context of an (alleged) convergence culture, young people are a key research population for exploring film consumption (Meers, 2004), mainly because they tend to adapt quickly and with ease to new technologies (Bennett and Robards, 2014). In the following sections, we first turn to sociological theories on taste and stratification. We then further explore taste cultures in film genre preferences.

\section{Taste cultures}

One prominent way in which sociologists interested in culture have identified stratified societal patterns throughout the past century is by studying taste cultures. These are found to reflect societal patterns, although it remains a topic of debate as to what extent this is the case. Chan and Goldthorpe (2005) identify three distinct leading arguments on taste cultures: (1) the individualization argument, (2) the homology argument, and (3) the omnivore-univore argument. The first is associated with postmodern consumption patterns and fits Jenkins' era of convergence culture: Consumers and audiences have no restraints in selecting a lifestyle and the associated (scattered) consumption pattern. Choice is the word that resurfaces here. 
The remaining two arguments state that consumption patterns do reflect stratified societal patterns, albeit in different ways. The homology argument, with Bourdieu (2009 [1979]) being the most prominent theorist, argues that one internalizes taste patterns that signal to which group one belongs. Higher classes for example enjoy high, or highbrow, culture, whereas lower classes enjoy lowbrow culture. Class is often measured through educational level. In this tradition, Kuipers (2006), for example, finds a taste hierarchy that fits educational lines amongst television audiences' tastes in humor. Others find the internalization of taste to extend beyond the class argument, and include other categories such as gender. In Flanders, for example, more mothers than fathers participate in high culture (Willekens, Daenekindt, and Lievens, 2014).

Lastly, the omnivore-univore argument takes social mobility into account. As coined by Peterson (1992), the higher strata in society are identified by a broad taste, taking experiences from different social strata with them as they climb the social ladder. The lower strata are identified by a confined taste. The omnivore-univore argument is set out in the field of music audiences, exploring and nuancing the concept (Peterson, 2005; Van Eijck, 2000; Warde, Wright, and Gayo-Cal, 2007). In contrasting these three arguments on stratification with that on individualization, this paper aims to identify (erosion) of existing societal structures.

Stratification has proved relevant in the context of film consumption. The classical elements of stratification (gender, educational level and ethnicity), for example, inform how one responds to, relates to, and understands a film (genre) (Staiger, 2005) - which in turn informs appreciation (Gripsrud, 2002). Film genre is a complex and multidimensional social construct. We embed our operationalization in the work on film genre by Altman (1984), who identifies three dichotomies in theories on film genre. For this paper, we embed the operationalization of film genres between the critical and the user vocabulary. In other words: We include the audiences in our analysis of film genres. This demarcation in our analysis of film genre means that we do not attempt to solve the extraordinarily complex matter of defining film genre. However, by taking this list of genres as a starting point, we can measure their overall appreciation. While this approach may limit our understanding of film genre as such, it will provide valuable insights into understanding contemporary structures in film consumption on the level of gender, educational level and ethnicity. We now turn to these elements of stratification in order to formulate our hypotheses. 


\section{Gender}

Gender and film has been a research focus ever since the medium emerged. In the Payne Fund studies, conducted in the late 1920s and the early 1930s, a difference between boys and girls watching film was found (Butsch, 2001). Studies that link film content to gender are found throughout time and remain until today (e.g., Hall, 2002; Lassner, 1944). Of most interest is the body of literature that repeatedly confirms differences in (film) genre preferences between genders. Men tend to prefer wilder and more action-driven films, whereas women tend to opt for romantic and quieter genres. Moreover, boys tend to disregard romance films more strongly than girls tend to disregard action-adventure films (Fischoff, Antonio, and Lewis, 1998; Krijnen and Van Bauwel, 2015; McRobbie, 2008).

The observed differences in film genre preferences between genders leads us to the first two hypotheses. The first, Hypothesis 1a, reads: Boys are more likely to appreciate action-driven film genres. The second hypothesis, $1 \mathrm{~b}$, exists in relation to Hypothesis 1a, and is centered on girls: Girls are more likely to appreciate quiescent film genres. We measure these preferences on the level of genre, which are subsequently linked to either action-driven or quiescent.

\section{Educational background}

When exploring educational background in relation to taste cultures, educational level serves as an operationalization of cultural capital. Coined by Bourdieu, cultural capital is only one of the different forms of capital that determine one's distinction within and between groups. Analyses of consumption patterns prove that groups with high amounts of cultural capital tend to prefer high culture, whereas groups with low levels of cultural capital tend to prefer low culture. Cultural capital is in its turn informed by educational background, both of the respondents as of their parents. It is, following Bourdieu (2009 [1979]), in the phase of one's upbringing that cultural capital is internalized, both at school and at home. This also proves true for media consumption. Daenekindt and Roose (2013), for example, emphasize appreciation of complexity in film by the higher educated in the Flemish population (Belgium). And the middle classes are eminently omnivorous: "The case of theatre, dance and cinema provides a yet more straightforward confirmation of the omnivore-univore argument than that of music" (Chan and Goldthorpe, 2005, p. 208).

To summarize: Educational background informs cultural capital, which in its turn is reflected in taste cultures. In what way education informs taste in film genre, however, remains subject to debate. On the one hand, there are theorists 
who argue that cultural capital leads to distinct taste patterns between different levels of cultural capital. On the other hand, there are theorists who argue that the level of cultural capital informs the number of appreciated genres. This translates into two contradicting hypotheses. Hypothesis 2a reads: Different levels of education correspond with different tastes in film genre. Hypothesis $2 \mathrm{~b}$ reads: The higher one is educated, the more film genres one appreciates. This brings us to a last element of stratification that we elaborate on in this paper: ethnicity.

\section{Ethnicity}

Ethnicity is not inherent to identity. However, in specific cases it can be rather prevalent. Cui (2015), for example, finds important differences between Asian students born in Canada or those "fresh off the boat" (p. 1163). He argues that first-generation students already internalized 'being Canadian', and only partly identify with those that were born in the country of their parents - even though they recognize their habits from home. The difference between the behavior of 'us' and 'them', especially important in theories on distinction, is exposed in the study of taste cultures.

Differences in film consumption are also found amongst diasporic communities in Belgium; for example, in Turkish and Indian film screenings in Antwerp, as explored by Vandevelde, Smets, Meers, Vande Winkel, and Van Bauwel (2011). They find that, although the selection of screened films is small and subjected to the selection process of exhibitors and distributors, strong diasporic film communities exist. Moreover, it is mainly this community that attends film screenings. Identification with a certain group through attending film screenings, coincides with the work of Dhoest (2012) on television audiences. He argues: "Television viewers do belong to national and ethnic groups, and they do share significant characteristics with fellow group members" (p. 99). In a later article, Dhoest (2015) again emphasizes differences and similarities among Flemish diasporic youth. However, the more generations live in Flanders, the less likely young people were to be interested in media from the country of origin of their parents or even grandparents.

Thus, ethnicity does in some specific cases inform taste in media, but this seems predominantly related to the origin of a film. Moreover, ethnicity quickly fades over generations in informing taste. Lastly, one's peers predominantly inform taste in media, be it from another 'foreign' ethnicity or between 'foreign' and 'Belgian' youth. Hypothesis 3 is therefore: Ethnicity does not inform taste in film genre over different generations. 


\section{Methods}

Between February and May 2015 we conducted a survey amongst a stratified (on school type and level) random sample of 1015 Flemish students aged 16-18. The questionnaires were completed during school hours. Questions were divided into 10 sections, including visiting the cinema, film-related activities, frequency of watching film and demographics. The operationalization of genre categories was built on existing genre classifications. The 15 genres are listed in the tables under Findings. Gender was either coded male or female. Level of education was measured on three levels: ASO (theoretical education), TSO (combines theoretical and practical education) and BS (practical education). The binary operationalization of ethnicity was grounded in the work of Dhoest (2015), which resulted in a group 'foreign' (the respondent or his or her parents are born abroad) and 'Belgian' (the respondent and his or her parents are born in Belgium).

To test our hypotheses, we conducted a regression analysis in SPSS. This type of analysis provides an estimation of how (well) belonging to a certain group predicts the evaluation of a genre. To be able to make in-group comparisons on the levels of educational background, dummy variables were constructed for each category. A positive significant value means that the student belonging to a specific subgroup is more likely to value that specific genre in comparison to the reference category, whereas a negative value means that one is less likely to value that genre in comparison to the reference category.

\section{Findings}

\section{Gender: The usual suspects confirmed}

Gender proves to be a very solid predictor in taste in genre (Table 1). Only four genres are not significantly related to gender. All others are. Girls are more likely to value Drama, Youth \& Family, Musical \& Music, and Romance. Boys have a somewhat larger spectrum of what they are likely to appreciate. The genres that are most likely to be appreciated by boys are Action \& Adventure, War \& Disaster, and Western. These coincide with the common understanding that boys are more prone to enjoy 'active' genres (Fischoff et al., 1998; Lassner, 1944). As such, Hypothesis 1a is confirmed. The same can be said for girls regarding a preference for more 'quiescent' genres, which confirms Hypothesis $1 \mathrm{~b}$. 
Table 1: Regression analysis of gender and genre preferences. ${ }^{\star} p<.05 ;{ }^{* \star} p<.01 ;{ }^{\star \star \star} p<.001($ male $=1)$

\begin{tabular}{|c|c|c|c|c|}
\hline Film genre & R2 & B & S.E. & $\beta$ \\
\hline Action \& Adventure & .110 & $.691^{\star * \star}$ & .063 & .332 \\
\hline Animation & .001 & -.054 & .071 & -.025 \\
\hline Detective \& Mystery & .000 & .022 & .074 & .010 \\
\hline Documentary \& Biography & .019 & $.328^{* * *}$ & .075 & .139 \\
\hline Drama & .223 & $-1.175^{\star \star \star}$ & .071 & -.472 \\
\hline Horror & .004 & $.186^{*}$ & .090 & .066 \\
\hline Youth \& Family & .111 & $-.704^{\star \star \star}$ & .064 & -.333 \\
\hline Comedy \& Humor & .003 & .094 & .059 & .051 \\
\hline Costume \& Historical Drama & .001 & -.062 & .074 & -.027 \\
\hline Musical \& Music & .182 & $-1.085^{\star * *}$ & .074 & -.426 \\
\hline War \& Disaster & .104 & $.826 * * \star$ & .078 & .322 \\
\hline Romance & .352 & $-1.545^{\star * *}$ & .068 & -.593 \\
\hline Science Fiction \& Fantasy & .023 & $.403^{* * *}$ & .085 & .151 \\
\hline Thriller \& Crime & .010 & $.235^{\star *}$ & .075 & .100 \\
\hline Western & .116 & $.765^{\star \star *}$ & .069 & .340 \\
\hline
\end{tabular}

\section{Educational background: Anything but horror}

The statistics on school level indicate that school level only partly explains taste in genre, with low $\mathrm{R}^{2} \mathrm{~s}$ (Table 2). Hypothesis $2 \mathrm{a}$ is thus partly accepted concerning taste in specific genres. Preferences for some genres are explained by educational level, others seem to be more universal, not significantly linked to a level of education. More interesting than specific genres is that an omnivore-univore argument emerges (Peterson, 1992). The more highly educated tend to dislike only few genres, that is, only those genres specifically related to groups enrolled in a lower level of education. In this research that is the horror genre, generally accepted as lowbrow culture (cf. Jancovich, 2000). These findings are in line with research by Bryson (1996) on music. She finds that with an increase of education, the tolerance for a variety of genres also increases. That is, any genre but heavy metal. The lower educated, on the other hand, tend to be characterized by univorism: They like specific genres, dismissing all others. Hypothesis $2 \mathrm{~b}$ is thus fully confirmed: ASO-level students are more likely to positively evaluate a higher number of genres, followed by TSO-level and BSO-level students. 
Table 2: Regression analysis of educational level and genre preferences. ${ }^{\star} p<.05 ;{ }^{* \star} p<.01 ;{ }^{* \star *} p<.001$.

\begin{tabular}{|c|c|c|c|c|}
\hline Film genre & $\mathbf{R 2}$ & B & S.E. & $\beta$ \\
\hline Action \& Adventure & .006 & & & \\
\hline TSO & & .143 & .080 & .064 \\
\hline BSO & & -.062 & 0.82 & -.027 \\
\hline Animation & .001 & & & \\
\hline TSO & & -.093 & .084 & -.040 \\
\hline BSO & & -.018 & .087 & -.007 \\
\hline Detective \& Mystery & .048 & & & \\
\hline TSO & & -.120 & .086 & -.049 \\
\hline BSO & & $-.592^{\star \star \star}$ & .088 & -.237 \\
\hline Documentary \& Biography & .021 & & & \\
\hline TSO & & $-.179 \star$ & .089 & -.072 \\
\hline BSO & & $-.424^{\star \star *}$ & .092 & -.164 \\
\hline Drama & .019 & & & \\
\hline TSO & & $-.329 \star \star$ & .094 & -.125 \\
\hline BSO & & $-.382^{\star \star *}$ & .097 & -.140 \\
\hline Horror & .025 & & & \\
\hline TSO & & $.403 * \star \star$ & .106 & .135 \\
\hline BSO & & $.506 * * *$ & .110 & .165 \\
\hline Youth \& Family & .006 & & & \\
\hline TSO & & -.048 & .080 & -.021 \\
\hline BSO & & .154 & .083 & .067 \\
\hline Comedy \& Humor & .001 & & & \\
\hline TSO & & .060 & .070 & .031 \\
\hline BSO & & .013 & .073 & .007 \\
\hline Costume \& Historical Drama & .021 & & & \\
\hline TSO & & $-.329 * \star *$ & .087 & -.161 \\
\hline BSO & & $-.214^{\star}$ & .089 & -.085 \\
\hline Musical \& Music & .011 & & & \\
\hline TSO & & $-.309 \star \star$ & .097 & -.115 \\
\hline BSO & & $-.223 * *$ & .100 & -.080 \\
\hline War \& Disaster & .001 & & & \\
\hline TSO & & .047 & .098 & .017 \\
\hline BSO & & -.053 & .101 & -.019 \\
\hline Romance & .011 & & & \\
\hline TSO & & 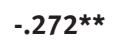 & .099 & -.099 \\
\hline BSO & & $-.290 \star *$ & .103 & -.102 \\
\hline Science Fiction \& Fantasy & .008 & & & \\
\hline TSO & & -.070 & .101 & -.025 \\
\hline BSO & & $-.286 * *$ & .104 & -.098 \\
\hline Thriller \& Crime & .016 & & & \\
\hline TSO & & .103 & .089 & .041 \\
\hline BSO & & $-.258^{\star *}$ & .092 & -.100 \\
\hline
\end{tabular}




\begin{tabular}{lcccc}
\hline Film genre & R2 & B & S.E. & \multicolumn{1}{l}{$\boldsymbol{\beta}$} \\
\hline Western & .001 & & & \\
TSO & & .045 & .087 & .019 \\
BSO & & .100 & .089 & .041 \\
\hline
\end{tabular}

\section{Ethnicity: Similar tastes}

Between Belgian and foreign groups, only few significant relations are found (Table 3 ). When a relation is found, $\mathrm{R}^{2} \mathrm{~S}$ are very small, with about $1 \%$ of likeliness explained. This means that ethnicity is not likely to account for genre evaluation. We therefore accept Hypothesis 3 and conclude that ethnicity is not likely to inform taste in film genre over different generations.

Table 3: Regression analysis of ethnicity and genre preferences.

${ }^{\star} p<.05 ;{ }^{\star \star} p<.01 ;{ }^{\star \star \star} p<.001$ (foreign $=1$ ).

\begin{tabular}{lllll}
\hline Film genre & R2 & B & \multicolumn{1}{l}{ S.E. } & \multicolumn{1}{l}{$\boldsymbol{\beta}$} \\
\hline Action \& Adventure & .001 & .067 & .081 & .027 \\
Animation & .010 & $-.264^{\star \star}$ & .085 & -.101 \\
Detective \& Mystery & .001 & .086 & .089 & .032 \\
Documentary \& Biography & .006 & $.219^{\star}$ & .091 & .078 \\
Drama & .003 & -.153 & .097 & -.052 \\
Horror & .000 & -.010 & .110 & -.003 \\
Youth \& Family & .011 & $-.265^{\star \star \star}$ & .082 & -.105 \\
Comedy \& Humor & .000 & .042 & .072 & .019 \\
Costume \& Historical Drama & .000 & -.028 & .089 & -.010 \\
Musical \& Music & .004 & -.192 & .099 & -.063 \\
War \& Disaster & .000 & .028 & .100 & .009 \\
Romance & .007 & $-.258^{\star}$ & .101 & -.083 \\
Science Fiction \& Fantasy & .000 & -.007 & .104 & -.002 \\
Thriller \& Crime & .001 & .086 & .091 & .031 \\
Western & .000 & -.044 & .088 & -.017 \\
\hline
\end{tabular}

\section{Conclusion}

In this article we introduced the need for understanding audiences' taste preferences from a sociological perspective. We found that gender proves to be a very strong indicator on film genre preferences. Level of education is a good indication 
of the versatility of genres that are positively evaluated. Ethnicity had little to no relation to taste in genre; tastes do not differ between Flemish youth and their peers with foreign roots. As such, the individualization argument (cf. Chan and Goldthorpe, 2005) does not surface in film genre preferences of Flemish youth. Audiences are more likely to venture out to keep up with their peers, informed by internalized values on taste that coincide with a social characteristic. In other words, cultural classifications inform taste. We can extend this finding in the light of participating audiences. As the more highly educated are less likely to dismiss a genre, this could indicate that they are more likely to venture out in search of the media experiences they want.

As with most social scientific research, the paper at hand provides some new lines of inquiry. We did, for example, not measure consumption, merely appreciation. Moreover, we confined ourselves to measuring gender, educational background, and ethnicity. This automatically leads to further questions on other means of stratification, such as including the educational background of the parents, urbanization, and economic position. But also, it leads to questions of combining the characteristics presented in this paper. What are, for example, the patterns of highly educated girls, versus those of highly educated boys? Furthermore, this paper identified structures in taste through identifying film genre preferences. Our quantitative approach provides good insights in these preferences within and between groups. For a full understanding of how these film genres are interpreted and why they are valued by youth in Flanders, obviously, qualitative interviews would provide a valuable addition to our understanding of film consumption.

\section{References}

Altman, R. (1984). A semantic/syntactic approach to film genre. Cinema Journal, 23(3), 6-18.

Bennett, A., \& Robards, B. (2014). Introduction: Youth, cultural practice and media technologies. In A. Bennett \& B. Robards (Eds.), Mediated youth cultures: The internet, belonging and new cultural configurations (pp. 1-7). Hampshire, New York: Palgrave Macmillan.

Biltereyst, D., \& Meers, P. (2011). The political economy of audiences. In J. Wasko, G. Murdock \& H. Sousa (Eds.), The handbook of political economy of communications (pp. 415-435).

Bird, S. E. (2011). Are we all produsers now? Convergence and media audience practices. Cultural Studies, 25(4-5), 502-516. doi:10.1080/09502386.2011.600532

Bourdieu, P. (2009 [1979]). Distinction: A social critique of the judgment of taste. London: Routledge.

Bryson, B. (1996). 'Anything but heavy metal': Symbolic exclusion and musical dislikes. American Sociological Review, 884-899. 
Butsch, R. (2001). Class and audience effects: A history of research on movies, radio, and television. Journal of Popular Film and Television, 29(3), 112-120.

Chan, T. W., \& Goldthorpe, J. H. (2005). The social stratification of theatre, dance and cinema attendance. Cultural Trends, 14(3), 193-212.

Couldry, N. (2011). More sociology, more culture, more politics. Or, a modest proposal for 'convergence' studies. Cultural Studies, 25(4-5), 487-501. doi:10.1080/09502386.2011. 600528

Couldry, N. (2012). Media, society, world: Social theory and digital media practice. Cambridge, Malden: Polity.

Cui, D. (2015). Capital, distinction, and racialized habitus: Immigrant youth in the educational field. Journal of Youth Studies, ahead-of-print, 1-16.

Daenekindt, S., \& Roose, H. (2013). A mise-en-scène of the shattered habitus: The effect of social mobility on aesthetic dispositions towards films. European Sociological Review, 29(1), 48-59.

Dhoest, A. (2012). Imagined communities of television viewers: Reception research on national and ethnic miority audiences. In H. Bilandzic, G. Patriarche \& P. J. Traudt (Eds.), The social use of media: Cultural and social scientific perspectives on audience research (pp. 87-104). Bristol, Chicago: Intellect.

Dhoest, A. (2015). Connections that matter: The relative importance of ethnic-cultural origin, age and generation in media uses among diasporic youth in Belgium. Journal of Children and Media, 9(3), 277-293.

Fischoff, S., Antonio, J., \& Lewis, D. (1998). Favorite films and film genres as a function of race, age, and gender. Journal of Media Psychology, 3(1), 1-9.

Gripsrud, J. (2002). Distinctions: Social difference, lifestyle and taste. In J. Gripsrud (Ed.), Understanding media culture (pp. 60-98). London: Hodder Education.

Hall, S. (2002). Tall revenue features: The Genealogy of the Modern Blockbuster. In S. Neale (Ed.), Genre and contemporary Hollywood (pp. 11-26). London: British Film Institute.

Jancovich, M. (2000). 'A real shocker': Authenticity, genre and the struggle for distinction. Continuum: Journal of Media \& Cultural Studies, 14(1), 23-35.

Jenkins, H. (2006). Convergence culture: Where old and new media collide. New York: New York University Press.

Krijnen, T., \& Van Bauwel, S. (2015). Gender and Media: Representing, Producing, Consuming. Abingdon: Routledge.

Kuipers, G. (2006). Television and taste hierarchy: The case of Dutch television comedy. Media, Culture \& Society, 28(3), 359-378. doi:10.1177/0163443706062884

Lassner, R. (1944). Sex and age determinants of theatre and movie interests. The Journal of General Psychology, 31(2), 241-271.

Maltby, R. (1999). Sticks, hicks and flaps: Classical Hollywood's generic conception of its audiences. In R. Maltby \& M. Stokes (Eds.), Identifying Hollywood's audiences: Cultural identity and the movies (pp. 23-41). London: British Film Institute Publishing.

McRobbie, A. (2008). Young women and consumer culture. Cultural Studies, 22(5), 531-550. doi:10.1080/09502380802245803

Meers, P. (2004). 'It's the language of film!': Young film audiences on Hollywood and Europe. In R. Maltby \& M. Stokes (Eds.), Hollywood abroad: Audiences and cultural exchange (pp. 158-175). London British Film Institute Publishing.

Peterson, R. A. (1992). Understanding audience segmentation: From elite and mass to omnivore and univore. Poetics, 21(4), 243-258. 
Peterson, R. A. (2005). Problems in comparative research: The example of omnivorousness. Poetics, 33(5), 257-282.

Staiger, J. (2005). Media reception studies. New York, London: NYU Press.

Van Eijck, K. (2000). Richard A. Peterson and the culture of consumption. Poetics, 28(2), 207-224.

Vandevelde, I., Smets, K., Meers, P., Vande Winkel, R., \& Van Bauwel, S. (2011). Bollywood and Turkish films in Antwerp (Belgium): Two case studies on diasporic distribution and exhibition. Javnost - the Public, 18(3), 55-70.

Warde, A., Wright, D., \& Gayo-Cal, M. (2007). Understanding cultural omnivorousness: Or, the myth of the cultural omnivore. Cultural Sociology, 1(2), 143-164.

Willekens, M., Daenekindt, S., \& Lievens, J. (2014). Whose education matters more? Mothers' and fathers' education and the cultural participation of adolescents. Cultural Sociology, 291-309. doi:10.1177/1749975514533686 